\title{
VERBRUIK OF INKOMEN ALS BELASTINGOBJECT
}

\section{door Prof. Dr. J. L. Meij}

1 De aangekondigde belastingverhogingen van de huidige Minister van Financiën hebben in het bedrijfsleven een aanzienlijke beroering gewekt. Blijkens hetgeen daarover in de pers werd gepubliceerd maakt men zich in verschillende branches ernstige zorgen over de verhoging van de omzetbelasting op de door die bedrijfstakken voortgebrachte goederen of diensten. Door het feit dat die zorgen ook door de consumenten worden gedeeld worden ze er niet minder op. Evenmin als omgekeerd de vrees van de consument gematigd wordt door overeenkomstige gevoelens bij de producent. De toegezegde verlaging van de inkomstenbelasting brengt hier, mede door de wijze waarop deze toegepast wordt, weinig olie op de golven van verontrusting. Afgezien van de vraag naar de oorzaken, die de overheid ertoe gebracht hebben te zoeken naar middelen om te streven naar verhoging van de inkomsten uit belastingen, kan worden gesteld dat de voorgestelde verhogingen van de zgn. indirecte belastingen als omzetbelasting en accijnzen in ieder geval de voorkeur verdienen boven verhoging van de directe belastingen als de inkomstenbelasting. Het valt daarom te betreuren dat ook de vennootschapsbelasting, een belasting op de winst van naamloze vennootschappen, een verhoging zal ondergaan. De helastingvoorstellen zijn daarom meer opportunistisch dan principieel te noemen. Niettemin komt het mij voor dat de eventuele bezwaren tegen de voorgenomen belastingverhogingen nog groter zouden hebben moeten zijn had de regering niet tevens een zekere verschuiving van directe naar indirecte belastingen in haar voorstellen belichaamd.

2 Hoewel belastingen in eerste instantie dienen om de overheidsuitgaven te financieren hebben zij daarnaast een aantal invloeden in de samenleving, waardoor zij als instrument van een doelbewuste economische of sociale politiek door de overheid kunnen worden gebezigd.

Zo kan men belastingen in het economisch leven hanteren om de voortbrenging te beïnvloeden. Men denke aan maatregelen als investeringsaftrek en toepassing van vervroegde afschrijving van aangeschafte duurzame produktiemiddelen. De invloed kan zowel stimulerend als remmend zijn. Hetzelfde geldt voor het verbruik. Zo kan men door belastingen bewust de bestedingen van de consument in het algemeen beperken. Ook hiervan levert het recente verleden voorbeelden. Eveneens kan men hem trachten te beperken in het gebruik van bepaalde goederen bijv. de beperking van het gebruik van geïmporteerde goederen door het heffen van invoerrechten. Als instrument van sociale politiek hanteert men belastingen eveneens indien men daardoor een sociaal schadelijk verbruik wil beperken bijv. door het heffen van accijnzen op bepaalde genotsmiddelen. Evenzo als instrument van sociale politiek hanteert men belastingen als men tracht daardoor een overheveling van beter gesitueerden naar minder bedeelden te bewerkstelligen. Indien men in de belasting bovendien een progressie legt veroorzaakt men daardoor op zich zelf reeds een nivellering van de welstandsverschillen. Aldus kan men met belastingen een reeks van effecten sorteren, die met de financiering der staatsuitgaven niet direct te maken hebben en zelfs daarvoor nadelig kunnen zijn. Zo zal men met prohibitieve invoerrechten wel het binnenlands verbruik van importgoederen beperken en daarmede de binnenlandse voortbrenging bevorderen, maar men zal 
er weinig aan hebben voor de financiering der overheidsuitgaven. Naar mate ze effectiever zijn m.b.t. het doel, dat er mee beoogd wordt, zullen ze minder opleveren.

3 Het is duidelijk, dat ook als men belastingen heft met een bepaald doel, hetzij om de staatsuitgaven te dekken, hetzij in het belang van een economisch, hetzij in dat van een sociaal doel, steeds nevenwerkingen zullen optreden met betrekking tot de andere doelstellingen. Zo zal de heffing van belastingen om de staatsuitgaven te dekken bepaalde economische en sociale repercussies veroorzaken. Indien we uitgaan van de belastingen als instrument voor de financiering der staatsuitgaven kan dus gevraagd worden naar de invloed, die de heffing heeft op economisch resp. sociaal gebied. Hoewel de invloed van een bepaald soort heffing in principe dezelfde zal zijn ongeacht haar onvang zal niettemin de mate van invloed bij uiteenlopende omvang zeer verschillend kunnen zijn. Dit mag bij de beoordeling van de betreffende heffing niet uit het oog worden verloren.

Een en ander betekent dus, dat men bij de beoordeling van een bepaald soort belastingheffing niet alleen te maken krijgt met de vraag: is het waarschijnlijk, dat daardoor het met de heffing beoogde doel wordt bereikt? Daarnaast zal men zich af moeten vragen met welke neveneffecten de heffing gepaard zal gaan, neveneffecten, die des te sterker worden naarmate de heffingen hoger zijn. Bovendien zal men zich rekenschap moeten geven van de eisen, die zowel aan contribuabelen als aan de administratie mocten worden gesteld teneinde het bedrag der verschuldigde belasting vast te stellen en te innen. Zowel de aangifte als de vaststelling van de aanslag zijn in vele gevallen allerminst een sincure.

Het is nu merkwaardig dat de belastingheffingen naar het inkomen en die naar de winst van vennootschappen, hoewel zij altijd nog naar opbrengst in ons land de bclangrijkste zijn, bijzonder ongunstig moeten worden beoordeeld, zowel wat hun neveneffecten aangaat als wat de offers verbonden aan de bepaling van hun hoogte betreft, en wel ongunstiger naarmate ze hoger zijn. In deze zin zou men de bekende slogan: 'ik houd van belastingen mits ze niet te hoog zijn' kunnen interpreteren.

$4 \mathrm{Bij}$ de aanvaarding van het ambt van hoogleraar van de Rijksuniversiteit te Groningen stelde ik in mijn inaugurele rede, dat bij de fiscale lasten, die de overheid in de jaren na de tweede wereldoorlog haar onderdanen moest opleggen, men niet kon volstaan met een eenvoudige verhoging van de tarieven, maar dat men tot een in beginsel ander systeem van belastingen zou moeten overgaan. Evenals practisch overal elders noodzaakt schaalvergroting tot verandering van systeem, bijna nimmer komt men er alleen met vergroting van de dimensies van hetzelfde systeem. Bij belastingheffing geldt dit nog a fortiori omdat naarmate de belastingen hoger zijn het streven tot afwenteling des te groter zal worden, terwijl bovendien de neiging tot ontduiking - in zekere zin ook een afwenteling - zowel als de neiging tot betwisting van de juistheid van het opgelegde bedrag sterker zal worden. Immers er staat meer op het spel. Dit betekent dat de neveneffecten van de heffingen, zowel als de offers verbonden met de bepaling van de hoogte der belastingen en die verbonden mot de inning, zullen toenemen naarmate de fiscale lasten hoger worden. De nevenwerkingen, die van belastingen op inkomen en winst uitgaan bestaan allereerst hierin, dat er voor de contribuabelen een belang ontstaat de voor de bepaling van het belastbaar inkomen aftrekbare kosten te verhogen. Uitgaven, 
die men niet verantwoord zou achten als er geen belasting van de winst of het inkomen zou worden geheven, worden verantwoord geacht en terecht indien de verkleining van het inkomen of de winst welke dientengevolge ontstaat ook een vermindering van de belasting ten gevolge heeft. Een winst- of inkomstenbelasting heeft dus ten gevolge dat men minder verantwoord kosten zal maken of een minder verantwoord beslag op produktiemiddelen zal leggen; minder verantwoord omdat de offers verbonden met het aanwenden der produktiemiddelen kleiner worden niet naarmate ze minder schaars worden maar naarmate de belasting hoger is. Een voorbeeld moge dit verduidelijken. Wanneer men bij een proportionele winstbelasting - als b.v- de vennootschapsbelasting - een opbrengst van $f 2.000$, - verkrijgt met een offer aan produktiemiddelen van $f 1000,-$ betaalt men bij een tarief van 50\% $f$ 500,- belasting terwijl eveneens $f$ 500,- uitkeerbare winst resteert. Verkrijgt men in hetzelfde produktieproces die opbrengst van $f 2000$,met een opoffering van produktiemiddelen van $f 1.500,-$ dan is de belasting $f 250$, - en de uitkeerbare winst eveneens $f 250$, - De verspilling van $f 500$,wordt dus voor de helft door de belastingvermindering opgevangen.

Men zou dus, lettend op de vermindering der uitkeerbare winst, ook kunnen stellen dat de grotere hoeveelheid produktiemiddelen slechts een offer van $f 250$,had veroorzaakt. Bij een tarief van $60 \%$ zou dit $f 200,-z i j n$. Indien de winst progressief belast wordt is uiteraard dit effect nog sterker.

Indien bij een winst van $f 1000$, - het tarief $75 \%$ zou zijn en bij een winst van $f 500$, - slechts $50 \%$ zou de verspilling van $f 500,-$ in het geheel geen invloed op de winst hebben. Een en ander moge voldoende zijn om duidelijk te maken dat winst- of inkomstenbelasting, al moge ze dan geen premie op de verspilling genoemd worden, de invloed van verspillingen op de winst mitigeren en dat des te sterker doen naar mate ze hoger zijn. Produktiviteitsverhoging mag dan ook van zodanige belastingen niet worden verwacht. Er ontstaat in tegendeel bij deze belastingen een vermenging van produktie- en consumptie-sfeer. Immers het kan zijn dat de verspilling een zekere bevrediging in de sfeer van het verbruik geeft, die preferabel is indien ze opgevangen wordt door de lagere belasting naar winst of inkomen. In dezelfde richting gaat dat de keuze tussen activiteit en leisure ten gunste van de laatste beïnvloed wordt en dat des te sterker naar mate de heffing hoger en naar mate ze meer progressief is.

$5 \mathrm{Er}$ is reeds opgemerkt dat in het bijzonder winstbelastingen - en dit geldt in het bijzonder voor die winstbelasting die als inkomstenbelasting van de particuliere ondernemer geheven wordt - moeilijker te heffen worden naar mate ze hoger zijn. De fiscus zal dan ook niet alleen stringente voorschriften moeten geven omtrent de wijze waarop de winst moet worden berekend maar ook zodanige voorschriften, die gemakkelijk controleerbaar zijn. De juistheid van de meeste aangiften kan niet worden gecontroleerd door goed in het vak geverseerde bedrijfseconomen, maar door controleurs, die aan de hand van duidelijke richtlijnen hun verantwoordelijk werk snel en efficient moeten kunnen doen. $\mathrm{Zij}$ zullen om een voorbeeld te noemen niet kunnen en willen treden in de beoordeling van een bij de winstbepaling door de contribuabele toegepaste vervangingsprijs.

Het is daarom begrijpelijk dat de administratie toch eigenlijk niet verder wil gaan dan het toepassen van fifo- en hoogstens lifo-waarderingen. Immers deze waar- 
deringen kan men aan de hand van zijn ontvangen facturen waar maken. Dit is in het algemeen niet het geval met vervangingsprijzen, niet alleen van duurzame produktiemiddelen maar ook van voorraden. Hier vindt de administratic tot op zekere hoogte de rechter tegenover zich. Immers de Hoge Raad heeft in een reeks van arresten sedert begin 1958 de toepassing van het ijzeren voorraad-stelsel als goed koopmansgebruik gequalificeerd. Hiermee kan althans wat de winst in haar totaliteit betreft hetzelfde resultaat verkregen worden als met toepassing van het vervangingswaarde-stelsel. Het is echter een misverstand te menen dat het ijzeren voorraad-stelsel gemakkelijker te controleren zou zijn. Immers het eist evenals trouwens het vervangingswaarde-stelsel, een beoordeling van de voorraadpositie teneinde te kunnen vaststellen wat in een bedrijf als ijzeren voorraad is aan te merken en vervolgens een beoordeling van vervangingsprijzen indien een manco, dat overeenkomstig dit stelsel moet worden aangevuld, aanwezig is. De bepaling van ijzeren voorraden kan men niet aan algemeen toepasbare normen binden. De beoordeling van de door de contribuabele vastgestelde ijzeren voorraad zal door de inspecteur en de rijksaccountant moeten geschieden. Niet in de eerste plaats omdat zij het wel zouden kunnen, maar omdat zij bevoegd zijn de verantwoordelijkheid voor compromissen te aanvaarden.

Door hantering van de door de administratie vastgestelde winstbepalingsvoorschriften en de door de rechter gegeven interpretaties m.n. van het begrip goed koopmansgebruik kan met gebruikmaking van de bevoegdheid van de inspecteur tot het aanvaarden van compromissen tenslotte tot een cijfer gekomen worden, waarvan belasting wordt geheven, een cijfer waarvan waarschijnlijk niemand meent dat het de winst is. Het is slechts een cijfer dat in zijn consequenties voor de administratie aanvaardbaar is en waarbij de contribuabele om welke reden dan ook zich neerlegt.

We krijgen hier de merkwaardige figuur, dat een van de belangrijkste bedrijfsbeslissingen niet gemaakt wordt door de bedrijfsleiding, maar door administratie en rechter, een figuur, die eigenlijk alleen past in collectivistische gemeenschappen waar de bedrijfsleiding slechts de directieven van de overheid heeft te volgen, niet in een samenleving waarin de leiders van bedrijven binnen bepaalde grenzen vrij zijn in het nemen van beslissingen, maar aan de andere kant daarvoor dan ook de verantwoordelijkheid moeten aanvaarden. Beslissingen tot onttrekken van middelen aan een bedrijf zijn in principe even belangrijk als beslissingen tot het investeren daarvan in het bedrijf. Indien de leiding voor die beslissingen de verantwoordelijkheid heeft te dragen moet zij ze ook zelf kunnen nemen. De belastingen naar inkomen en winst van ondernemingen hevelen de bevoegdheid tot het beslissen over het onttrekken van middelen over naar instanties buiten de bedrijfsleiding, zonder echter ook de verantwoordelijkheid daarvoor over te hevelen.

6 Wanneer men belastingen heft niet naar inkomen of winst, maar naar het verbruik van produktiemiddelen en eindprodukten dus naar het verbruik van producent en consument ontstaan geheel andere neveneffecten, die in het algemeen veel gunstiger werken zowel op de individuele onderneming als op de maatschappij in haar geheel. Bovendien zijn de criteria waarnaar geheven wordt veel eenvoudiger en gemakkelijker te bepalen. Men behoeft zich daarbij niet in ingewikkelde economische of bedrijfseconomische vraagstukken te begeven. Hetgeen hier voor 
belastingen naar het verbruik opgemerkt wordt geldt uiteraard ook voor omzetbelastingen. Wanneer een onderneming meer belasting moet betalen naar mate zij meer produktiemiddelen verbruikt zal zij gestimuleerd worden met deze produktiemiddelen zuinig om te gaan. Elke inefficiency wordt a.h.w. dubbel gestraft, eenmaal door het verlies van het verspilde produktiemiddel zelf, eenmaal door de daarop drukkende belasting. Een omzetbelasting op produktiemiddelen als bijv. grondstoffen, hulpmaterialen, machines e.d. zou dit effect kunnen sorteren. Ook een omzetbelasting op verbruiksgoederen heeft dezelfde invloed zelfs al zou het toegelaten zijn een belasting door prijsverhoging af te wentelen. Immers de onderneming die door efficienter te produceren de omzetbelasting met prijsverlaging kan compenseren is in het voordeel bij degene die daartoe niet in staat is. Men zou hier de tegenwerping kunnen maken dat wanneer efficienter produktie mogelijk geweest zou zijn ook zonder verbruiksbelasting of omzetbelasting de onderneming die groter efficientie betracht een voorsprong heeft op zijn concurrenten en dat dus die voorsprong bepaald niet door de belastingheffing veroorzaakt wordt. Men vergeet daarbij dat werkwijzen, die met een grondstoffenprijs zonder belasting nog juist lonend zijn, dit niet meer behoeven te wezen als de grondstoffenprijzen met het bedrag van de belasting zijn verhoogd. De grensbedrijven zullen dus of moeten verdwijnen of tot grotere efficientie moeten komen. Het is duidelijk dat de stimulans tot dit laatste groter is als het gaat om te zijn of niet te zijn, dan wanneer het alleen gaat om een reeds bevredigend resultaat nog wat bevredigender te maken.

Samenvattend zou dus kunnen worden gezegd, dat verbruiksbelastingen resp. omzetbelastingen zullen resulteren in een tendens naar en stimuleren tot het bereiken van een nieuw evenwicht in het economisch systeem op een niveau van groter efficientie in de produktie. $\mathrm{Zij}$ laten niet alleen het volle voordeel van de grotere efficientie aan de producent, maar vergroten het bovendien. Belastingen op inkomen en winst uit ondernemingen laten hoogstens het bestaande evenwicht intact, althans indien de heffing zich tot de overwinsten, d.z. de winsten boven de normale vergoeding voor het beschikbaar stellen van kapitaal en eventueel arbeid door de winstgerechtigden, zou beperken. Elk voordeel verkregen door meer efficiente produktie zal men echter met de fiscus moeten delen.

Belastingen naar winst en inkomen gaan impliciet uit van een statische conceptie, een evenwichtstoestand, waarin alle mogelijkheden tot grotere efficientie volledig zijn benut, waarin nieuwe mogelijkheden zich niet meer zullen voordoen. Het is duidelijk dat een dergelijke conceptie vrijwel in alle opzichten tegengesteld is aan de huidige werkelijkheid. In zekere zin zou men dus kunnen stellen, dat belastingen naar winst en inkomen voortvloeien uit een verouderde en steeds meer verouderende conceptie van het economisch leven.

7 Men is waarschijnlijk niet ver mis als men veronderstelt dat het taaie leven dat de zgn. directe belastingen in het sterk veranderend karakter van het economisch leven vertonen, te danken is aan het feit dat men gelooft dat deze heffingen in overeenstemming zifjn met het draagkrachtbeginsel. Dit betekent dat het vooral de nevenwerking van een vermindering in de ongelijkheid van de verdeling van het maatschappelijk inkomen is, die men verkieslijk acht.

De vraag kan echter opgeworpen worden of men van de overheid niet te veel vergt door haar als meter van de draagkracht en egalisator van de inkomensverdeling te laten optreden. Een interpersonele nutsvergelijking waarop een dergelijke 
meting en egalisatie zou moeten berusten toch is onmogelijk. Bovendien doet zich hier eigenlijk dezelfde moeilijkheid voor als werd gesignaleerd bij de winstbelastingen. Daar bepaalde feitelijk de fiscus wat aan de onderneming zou kunnen worden onttrokken en liet haar dan in ieder geval de helft van het aldus bepaalde bedrag ook feitelijk onttrekken. Hier bepaalt nu de fiscus wat men aan zijn verbruikshuishouding zal kunnen onttrekken, maar hier evenals in het geval van de onderneming weer zonder zich om de vraag te bekommeren of na de onttrekking de doeleinden van de huishouding nog wel kunnen worden bereikt en hier ook zonder voor die onttrekking verantwoordelijkheid te anvaarden. Belast men echter het verbruik dan beslist de contribuabele wat hij besteden wil en laat hem daarvan de consequenties dragen. Het is niet aan te nemen dat zijn beslissingen zodanig zullen uitvallen dat de verbruiksbelastingen nagenoeg niets zullen opleveren, zelfs is dat niet het geval indien de meest elementaire verbruiksgoederen zouden zijn vrijgesteld of slechts door een zeer laag tarief zouden worden getroffen. Immers de vermindering van het verbruik zal betekenen toename van de besparingen. Aangenomen kan worden dat deze besparingen worden geïnvesteerd men zal ze niet renteloos laten - en dan betekent dit weer verbruik van produktiemiddelen. Er heeft dus alleen een verschuiving plaats van het consumptieve naar het produktieve verbruik. Het vrijstellen van de voornaamste goederen van eerste levensbehoeften behoeft dus geen nadelig effect op de belastingopbrengst te hebben.

Men mag hierbij ook niet vergeten dat hoge tarieven voor goederen van meer of minder luxe minder invloed zullen hebben als de consument geen inkomstenbelasting hoeft te betalen. Hoe hoger het te besteden inkomen wordt hoe minder elastisch de vraag naar goederen wordt ongeacht het meer of minder luxueuse van die goederen. Ongunstige nevenwerkingen op het gebied der inkomensverdeling behoeven er daarom van verbruiksbelastingen ook niet uit te gaan. In tegenstelling tot belastingen naar inkomen en winst voorkomen zij dat de overheid zich ook hier heeft te mengen in een beslissing waarvoor alleen het hoofd der betrokken huishouding verantwoordelijk is en verantwoordelijkheid kan aanvaarden.

Het mag in dit verband niet onvermeld blijven dat in collectivistische landen waar de staatsbemoeiing veel verder pleegt te gaan dan in de zgn. vrije wereld merkwaardig genoeg de verbruiksbelastingen een veel grotere plaats innemen bij de financiering van de financiële behoeften van de overheid.

8 Een overgang naar belastingen geheven naar het verbruik van produktiemiddelen en consumptiegoederen zal tevens een belangrijke vereenvoudiging betekenen in administratief opzicht. Terwijl de winst, in de zin van het bedrag dat over een bepaalde periode in een onderneming gevormd daaraan zou kunnen worden onttrokken, een grootheid is waarvan de bepaling wel het meest delicate en gecompliceerde vraagstuk in het leven der onderneming vormt, is de vaststelling van in het voortbrengingsproces verwerkte produktiemiddelen, zowel als de bepaling van de verkochte produkten een aangelegenheid die betrekkelijk weinig problemen op kan leveren. Hier kan men inderdaad steunen op objectieve gegevens. Van uiteenlopende inzichten kan nauwelijks sprake zijn. Bovendien zijn het gegevens die gemakkelijk geproduceerd en gecontroleerd kunnen worden. Ieder die over enige comptabele kennis beschikt kan de verantwoording hiervan tot in details controleren. Veelal zal men echter zelfs kunnen volstaan met een meer globale controle aan de hand van uit de praktijk bekende normen. 
Verwacht mag dan ook worden dat de administratie van deze belastingen betrekkelijk weinig arbeid zal kosten en bovendien dat die arbeid minder gequalificeerd zal behoeven te zijn. De vaststelling van de verschuldigde belasting zal veel minder dan thans het geval is het resultaat zijn van onderhandelingen van administratie en contribuabele. Het compromissoir karakter van de aanslagregeling zal goeddeels verdwijnen. Daarmee heeft het belastingrecht de kans inderdaad weer recht te worden.

De besparing an arbeid die de minder ingewikkelde administratie der verbruiksbelastingen veroorzaakt, niet alleen voor de fiscus maar ook voor de contribuabelen en hun adviseurs, betekent op zich reeds een belangrijke bijdrage tot bevordering der produktiviteit. De overgang naar de hierbedoelde belastingen betekent echter ook een belangrijke bijdrage tot de rechtszekerheid.

Alles bijeengenomen valt het te betreuren dat de huidige belastingvoorstellen geen principiële frontverandering betekenen. $\mathrm{Er}$ was een goede gelegenheid geweest het gebied der verbruiksbelastingen - waaronder de omzetbelasting - aanzienlijk uit te breiden en dat der inkomens- en winstbelastingen in te perken. De nodig geachte verhoging van inkomsten ware dan verkregen op een wijze, die voornamelijk gunstige nevenwerkingen zowel in economisch, sociaal als in fiscaaladministratief opzicht had gesorteerd. Daardoor zou de totale last die op de maatschappij wordt gelegd, aanzienlijk minder en aanzienlijk gemakkelijker te dragen zijn geweest dan thans het geval zal blijken te zijn.

9 De hier door mij ontwikkelde gedachten zullen voor het merendeel van de lezers van dit blad niet nieuw zijn. Niettemin waren de huidige belastingvoorstellen aanleiding nog eens op deze inzichten terug te komen. $\mathrm{Zij}$ worden trouwens thans meer gedeeld dan in het verleden.

Hoewel in de buitenlandse literatuur het vraagstuk van de vaststelling van belastingen naar inkomen en winst vs. die naar verbruik of omzet van produktiemiddelen en verbruiksgoederen tot vele interessante beschouwingen aanleiding heeft gegeven, is hier te lande de literatuur vooral geconcentreerd geweest op de problematiek verbonden met de heffing van belastingen naar inkomen en winst.

Aan de noodzaak, die ik in 1948 reeds bepleitte werd nimmer tegemoet gekomen.

Hopelijk dat thans de tijd eindelijk rijp is voor een bezinning op de grondslagen van ons belastingstelsel. Merkwaardig - als symptoom - mag daarbij het feit worden gereleveerd dat ongeveer een jaar geleden door de nieuwbenoemde hoogleraar in de leer der openbare financiën aan de Katholieke Economische Hogeschool te Tilburg, een hervorming van ons belastingstelsel werd bepleit, op dezelfde gronden als in deze en vroegere beschouwingen mijnerzijds werd voorgestaan ${ }^{1}$ ). Daar op geen enkele wijze van enige bekendheid met de door mij geproduceerde literatuur blijkt moet ik - gelukkig - aannemen dat deze jonge collega geheel onafhankelijk daarvan tot dezelfde conclusies is gekomen. Alleen zijn verdediging van een algemene - op Kaldor geïnspireerde - ,expenditure-tax" naast de specifieke verbruiksbelastingen zal men in mijn beschouwingen niet aantreffen. $\mathrm{Zij}_{\mathrm{ij}}$ komt mij voor niet noodzakelijk en zelfs niet gewenst te zijn. Dit is een hoofdstuk op zich dat hier momenteel ook des te beter buiten beschouwing kan blijven omdat de instelling daarvan nog een forsere ingreep zou betekenen dan de geleidelijk door te voeren

1) Th. Stevens: Hervorming van ons Belastingstelsel, or. Tilburg 1964. 
verschuiving in de richting van verbruiksbelastingen op produktiemiddelen en eindprodukten²).

2) Op een vergelijking van ,indirecte” en „directe” belastingen als instrument van economische politiek werd hier niet uitvoerig ingegaan. Dit is een hoofdstuk op zich. In principe behoeft echter de heffing van, indirecte" belastingen als zodanig niet te worden achtergesteld bij die van directe belastingen. Integendeel ook als instrument van economische resp. sociale politiek zijn ,indirecte" belastingen veelal te prefereren. Wellicht doet zich een mogelijkheid voor hierop in een volgend artikel in te gaan. 